\title{
TEORIA DAS ORGANIZAÇÕES E A NOVA SOCIOLOGIA ECONÔMICA: UM DIÁLOGO INTERDISCIPLINAR
}

RESUMO

Este trabalho pretende abordar algumas contribuições teóricas para ampliar o diálogo interdisciplinar entre a teoria das organizações e a nova sociologia econômica. Para tanto, os autores fazem inicialmente uma reconstituição do ressurgimento dos estudos da sociologia econômica. Em seguida, apresentam a problemática presente na interface da nova sociologia econômica e da teoria das organizações. Depois avançam em direção à construção interdisciplinar, indicando as contribuições que a teoria das organizações pode dar para a nova sociologia econômica e vice-versa. Vários temas e enfoques hoje desenvolvidos separadamente pelas duas disciplinas podem ganhar em riqueza e profundidade para ambas se o esforço de construção interdisciplinar for realizado. Assim, o interesse dos autores é auxiliar esse processo, indicando perspectivas de trabalho conjunto para pesquisadores de ambos os campos.

\section{Maurício Serva \\ PUC-PR}

\section{Carolina Andion}

UNIFAE

ABSTRACT The intention is to raise some theoretical contributions to broaden the dialogue between organizational theory and economics sociology. First mention is made of the reappearance of studies in economics sociology to be followed by problems presently found in the interface of the two disciplines. An interdisciplinary elaboration follows pointing out the contributions that each discipline can bring to the other. Many questions and perspectives today developed separately in both disciplines can be enriched and deepened if an effort for interdisciplinary elaboration is carried on. The authors' interest is top help in this process, suggesting possibilities of a joint research effort for the areas of organizational theory and economic sociology.

PALAVRAS-CHAVE Teoria das organizações, sociologia econômica, abordagem interdisciplinar, desenvolvimento da teoria das organizações, desenvolvimento da sociologia econômica.

KEYWORDS Organization theory, economic sociology, interdisciplinary approach, advancement of organization theory, advancement of economic sociology. 


\section{INTRODUÇÃo}

Desde os anos 1980, um dos campos que tem experimentado maior crescimento nas ciências sociais é o da sociologia econômica. O vigor que caracteriza não somente a quantidade, mas também a qualidade dos trabalhos realizados atesta o fortalecimento progressivo desse campo de estudos. Uma das consequêencias desse vigor é a promoção da institucionalização do campo nos meios acadêmicos internacionais. Podem ser citados como exemplos a iniciativa de Amitai Etzioni, com a criação em 1989 da Society for Advancement of Socio-Economics (SASE) nos EUA (hoje, com membros em mais de 50 países), a criação de uma rede temática em sociologia econômica no interior da Associação Francesa de Sociologia, a instalação de um comitê de pesquisa em sociologia econômica na Associação Internacional de Sociólogos de Língua Francesa, além do lançamento de várias revistas acadêmicas e a realização anual de diversos congressos internacionais. Embora no Brasil esse movimento tenha demorado um pouco a se manifestar, já começa a dar alguns sinais importantes: a revista Sociedade e Estado, da UnB, dedicou sua edição de janeiro-junho de 2002 à sociologia econômica, sendo a primeira coletânea de trabalhos nesse campo publicada no Brasil; em novembro de 2003, numa promoção conjunta dos programas de doutorado em sociologia política e ciências humanas da UFSC, foi realizado o I Seminário sobre Sociologia Econômica naquela universidade; nos anos de 2004 e 2005, o Encontro Anual da Anpocs promoveu uma seção de apresentação de trabalhos sobre o tema "análise sociológica dos fenômenos econômicos"; e em 2005, a RAE-revista de administração de empresas lançou o Fórum Especial de Sociologia Econômica.

Tendo em vista o crescimento vertiginoso do campo da sociologia econômica e, principalmente, o fato de que muitos de seus temas são também temas da teoria das organizações, pretendemos aqui apresentar uma proposta de diálogo interdisciplinar entre esses dois campos do conhecimento. Trata-se, evidentemente, de um trabalho de aprofundamento teórico, por meio do qual temos como objetivo maior oferecer uma contribuição para o enriquecimento mútuo desses campos. Dessa forma, queremos contribuir para fertilizar o terreno da fronteira entre tais campos, com benefícios para ambos. Alain Caillé, fundador de uma das correntes da sociologia econômica chamada de Mouvement Anti-Utiliariste en Sciences Sociales (MAUSS), explicita bem essa necessidade de se em- preenderem esforços de aproximação interdisciplinar do tipo que ora tentamos. "Nas oficinas especializadas de que falamos hoje, as pessoas (pesquisadores) se dedicam a produzir peças novas e esquecem de abrir os armários onde achariam, provavelmente, o que procuram e num estado de qualidade inegável" (Caillé, 1994 , p. 8). Parafraseando Caillé, tentaremos então "abrir os armários" tanto da teoria das organizações como da sociologia econômica. Certamente encontraremos algo de valioso dentro deles para a construção da interdisciplinaridade.

\section{CONSIDERAÇÕES DE ORDEM METODOLÓGICA}

Antes de adentrarmos o tratamento específico das teorias aqui discutidas, gostaríamos de prestar esclarecimentos sobre a metodologia que presidiu a elaboração deste estudo. O trabalho que aqui apresentamos é de natureza teórica, que visa auxiliar o desenvolvimento da produção do conhecimento na teoria das organizações e na sociologia econômica. Não obstante, cremos que tal desenvolvimento poderá trazer conseqüências positivas de ordem prática, uma vez que atualmente a Administração e a Sociologia fazem parte da formação de diversas especialidades profissionais. Voltar a atenção às teorias organizacional e sociológica, tendo como enfoque as possibilidades de construção de saberes interdisciplinares, pode gerar, na prática, conseqüências benéficas para as organizações e para os profissionais que nelas atuam, pois a concretização do conhecimento administrativo se manifesta por meio das organizações (Benson, 1977).

Uma vez que o presente trabalho trata do aprofundamento teórico, então nossos dados são constituídos por teorias entendidas como tentativas de interpretação e compreensão da realidade - no caso a realidade das organizações produtivas -, como veremos mais adiante. Esta proposta de construção interdisciplinar implica os seguintes procedimentos metodológicos:

- empreender uma breve reconstituição do processo de ressurgimento da sociologia econômica, uma vez que ela nasce com os clássicos (Karl Marx, Émile Durkheim e Max Weber), mas é retomada em novas bases nas últimas décadas, por isso a idéia de "ressurgimento";

- abordar, sob a perspectiva de uma "problematização", a interface entre uma das correntes específicas que integram o campo atual da sociologia econômica - notadamente a corrente denominada "nova sociologia econômica" (NSE) - e a teoria das organizações, visando 
situar o leitor na fronteira dos dois campos;

- indicar algumas das contribuições que a teoria das organizações pode oferecer à NSE;

- indicar potenciais contribuições da NSE à teoria das organizações.

\section{RESSURGIMENTO DA SOCIOLOGIA ECONÔMICA}

A sociologia econômica é tributária do trabalho dos clássicos da sociologia Karl Marx, Émile Durkheim e Max Weber, que lançaram as bases desse campo disciplinar. Porém, da década de 1920 até os anos 1960, esse diálogo entre a sociologia e a economia ficou negligenciado. A sociologia nesses anos "se limitaria aos estudos das conseqüências sociais das inovações e das condições sociais das transformações econômicas" (Lévesque, Bourque e Forgues, 2001, p. 20).

$\mathrm{Na}$ década de 1980, a sociologia econômica ressurge com intensidade, voltando seu interesse para as bases deixadas pelos seus precursores, ou seja, os estudos dos fenômenos econômicos à luz de uma abordagem sociológica. A sociologia econômica nessa década, por meio de suas diferentes correntes, passa então a se contrapor aos fundamentos da ciência econômica neoclássica, na tentativa de demonstrar que o mercado e os demais fenômenos econômicos são construções sociais. Todavia, é bom ressaltar que esse ressurgimento não implicou uma produção harmônica: os autores se subdividem em várias linhas no interior do campo. Se, por um lado, isso apresenta um aspecto preocupante - o risco de rupturas internas ou até de um novo "adormecimento" -, por outro lado, tal configuração atesta a riqueza do movimento, ensejando debates vigorosos na abordagem de seus temas, e pode até se constituir em fontes de energia para o seu próprio avanço.

Para melhor entender o campo atual da sociologia econômica é importante realizar algumas distinções entre os seus representantes. Primeiramente, destaca-se a clivagem entre os autores clássicos, que deram origem ao campo e construíram as suas bases - Émile Durkheim, Max Weber, Karl Marx, Tornstein Veblen, Vilfredo Pareto, Joseph Schumpeter, Marcel Mauss e Karl Polanyi - e os autores que, principalmente após a década de 1980, constituem a sociologia econômica contemporânea. Sob o guarda-chuva desta última se incluem várias correntes e autores (Lévesque, Bourque e Forgues, 2001).

Destacam-se, de um lado, os trabalhos dos autores francófonos, mais relacionados à sociologia e à antro- pologia, representados pelo MAUSS (como Alain Caillé, Serge Latouche e Jacques Goudbout), pela economia solidária e plural (como Bernard Eme, Jean-Louis Laville, Bernard Perret, Guy Roustang e Benoît Lévesque), pela escola da regulação (como Michel Aglietta, Alain Lipietz e Robert Boyer), e pela escola das convenções (como Luc Boltanski, Laurent Thenévot e Jean-Pierre Dupuy). Tais autores, além de realizarem uma crítica aos pressupostos da economia neoclássica, fazem também propostas em termos de transformação social, redefinindo o que deve ser entendido por atividade econômica e buscando responder aos desafios colocados pelos novos contextos da modernidade.

De outro lado, se enquadram os trabalhos dos autores de língua inglesa, abrangendo a NSE (como Mark Granovetter, Viviana Zelizer e Neil Fligstein), o institucionalismo (como John K. Galbraith, Gunnar Myrdal e Geoffrey Hodgson), e a socioeconomia (como Amitai Etzioni, Paul Lawrence e Paul Stern). Na sua maioria, os estudos elaborados nessas duas últimas correntes se contrapõem à economia neoclássica, mas não se concentram em propor alternativas contundentes. Apenas buscam dialogar com os autores da economia, visando um enriquecimento desta, a partir da contribuição dos estudos sociológicos.

Portanto, existem diversas correntes no âmbito da sociologia econômica, cada uma delas com seus conceitos centrais, suas opções de pesquisa, seus autores e obras-chave. Em um trabalho de mapeamento recente, Lévesque, Bourque e Forgues (2001) identificaram nada menos que nove correntes internas. Entretanto, pode-se observar que tais correntes têm em comum o fato de realizarem uma crítica aos fundamentos da economia neoclássica e de afirmarem a construção social da economia. Swedberg (1994, p. 35) descreve a sociologia econômica como "o conjunto de teorias que se esforçam por explicar os fenômenos econômicos a partir de elementos sociológicos". Neste trabalho estaremos nos concentrando na corrente da nova sociologia econômica (NSE) por nos parecer esta mais próxima da teoria das organizações, em função da semelhança de temas adotados.

\section{PROBLEMATIZAR A INTERFACE}

A NSE não enfoca apenas a crítica à economia neoclássica, mas se interessa em participar dos debates sobre a economia. Os autores da NSE, mais do que "reformular" a economia neoclássica, buscam dialogar com ela e 
enriquecê-la, utilizando, muitas vezes, os mesmos conceitos e instrumentos que os economistas. Como destaca Granovetter, considerado o fundador da NSE, "ora, nossa ambição é mostrar que as teses neoclássicas seriam reforçadas, mesmo em seu domínio mais central, se lhes fosse acrescentada uma perspectiva sociológica" (Granovetter, 2001, p. 207). Outro autor renomado afirma que "diferentemente dos clássicos, a moderna sociologia econômica dos mercados raramente conecta as suas idéias teóricas a uma visão de sociedade ou à mudança social. Ao contrário, a maioria dos estudos enfoca o seu objeto empírico e a literatura no qual ele está inserido" (Fligstein, 1996, p. 8).

Os pressupostos centrais da NSE afirmam: toda ação econômica é uma ação social; a ação econômica é socialmente situada; e as instituições econômicas são construções sociais (Lévesque, Bourque e Forgues, 2001). Tais pressupostos vêm confirmar a importância da dimensão sociológica e se contrapor a uma visão eminentemente utilitarista dos fenômenos econômicos. Porém, para ir além, parece necessário que a NSE avance no aprofundamento de algumas questões que ela mesma deixa em aberto, quais sejam: Quais são as características dos atores sociais que agem no campo econômico? De que modo podem-se descrever os campos socioeconômicos, nos quais as organizações são os principais atores? Quais os tipos de racionalidade que movem a ação desses atores e os fazem atuar no mercado? De que modo e por meio de quais instrumentos as relações de poder influenciam as organizações e os mercados? Até que ponto a inserção social dos mercados se contrapõe à "mercantilização" dos espaços da vida?

Como afirma Perret (2001, p. 9), "a crítica da lógica de mercado não pode verdadeiramente se desenvolver senão se emancipando do quadro de pensamento da ciência econômica". Esse autor coloca que, para não assumir um papel subordinado em relação à economia, a sociologia econômica deveria acompanhar e teorizar sobre as grandes "renegociações" do papel da economia na atualidade. Dessa forma, ele sinaliza para uma lacuna das proposições da NSE que, assumindo um posicionamento pretensamente "neutro", poderia inclusive vir a reforçar um processo de "mercantilização" dos espaços da vida. Assim, percebe-se que a NSE não pode ser considerada como uma corrente filiada à sociologia eminentemente crítica, uma vez que ela não é centrada num projeto de transformação profunda da sociedade.

$\mathrm{Na}$ medida em que a NSE não rompe radicalmente com a economia neoclássica, e sim trava um diálogo com ela, é evidente que também se aproxima de uma parte da teoria das organizações, estudando alguns dos temas pelos quais, ao longo da sua história, a Administração também se interessou: o funcionamento do mercado e de suas instituições, as relações de produção e o consumo. Cabe ressaltar que no mesmo momento em que o diálogo entre a sociologia e a economia se arrefeceu, entre as décadas de 1920 e 1960, ocorreu a expansão dos estudos no campo da Administração, ou seja, durante o período do fordismo. Este é aqui entendido numa acepção mais ampla, como sendo o modelo geral de desenvolvimento econômico implantado após a Segunda Guerra Mundial nos Estados Unidos, na Europa Ocidental e no Japão. É nessa época que são elaboradas a maioria das teorias das organizações de cunho funcionalista, assim como é no final da década de 1960 que se inicia o questionamento a esse paradigma e aumenta a influência dos estudos críticos no campo da análise das organizações. Isso vai ampliar o diálogo com as ciências sociais, que teve seu início na década de 1930 com os estudos de Elton Mayo em Hawthorne, propiciando a realização das pesquisas no campo das relações humanas e descrevendo a organização como um sistema social. Desde então os estudos e pesquisas no campo da teoria das organizações se intensificaram, promovendo um diálogo entre os aspectos referentes à economia e à sociologia, mas também a outras disciplinas das ciências humanas, tais como a antropologia, a história e a psicologia.

Atualmente, a teoria das organizações está longe de ser apenas um conjunto de prescrições que ensinam aos gerentes "o que fazer", ou, como afirma Bourdieu em seu artigo sobre os campos econômicos,

a literatura do management das escolas de gestão preenche uma função parecida com aquela dos textos de juristas do século XVI e XVII que contribuíram para a construção do Estado, ao contrário de apenas descrevêlo: concebida para o uso dos gestores, atuais ou potenciais, ela oscila entre o positivo e o normativo e repousa fundamentalmente sobre uma superestimação da parte deixada às estratégias conscientes em relação aos limites e estruturas e à disposição dos dirigentes (BOURDIEU, 1997, p. 59).

Nessa passagem, que é uma das poucas citações encontradas sobre os estudos da teoria das organizações pelos autores da NSE, percebe-se uma visão calcada no paradigma funcionalista, o qual desde os anos 1970 
vem sendo criticado no âmbito dos estudos organizacionais por diferentes autores (como Benson, 1977; Chanlat e Dufour, 1985; Guerreiro Ramos, 1989; Chanlat, 1990). Sem desconsiderar a influência do paradigma funcionalista e seus desdobramentos nos estudos organizacionais, pode-se afirmar que nas últimas três décadas, principalmente a partir da influência dos estudos críticos, alguns autores do próprio campo têm assumido uma atitude reflexiva - tão valorizada pelo próprio Bourdieu - analisando os pontos cegos e defendendo uma teoria das organizações crítica e menos normativa.

Tendo por base esses autores e os desdobramentos mais recentes que ocorrem nos estudos organizacionais, propomos neste artigo maior aproximação entre os estudos da NSE e os da teoria das organizações, o que tem ocorrido ainda de forma muito tímida, localizada $^{1}$ e sem um real esforço de construção interdisciplinar. A defesa desse argumento se justifica ao pensarmos que a NSE se interessa por analisar os processos econômicos essenciais por meio da sociologia. Tal análise não pode se abster de levar em consideração as organizações como um ator central e, em última instância, de considerar o fenômeno da "sociedade de organizações", onde essas passam a assumir formas variadas e papéis diversos (Etzioni, 1976). A centralidade que assumem as organizações na constituição da sociedade e do mercado na modernidade faz com que qualquer estudo que pretenda entender melhor essas esferas tenha que considerar o papel das organizações. Como afirma Etzioni, tais organizações não são "satélites", mas são integrantes da sociedade, e, por isso, é importante conhecer as suas dimensões constitutivas e suas formas de inter-relação, que são estabelecidas "nos processos de troca, conflito ou cooperação e negociação, todos influenciados por fatores ecológicos, culturais e de poder" (Etzioni, 1976, p. 175).

Do nosso ponto de vista, para que a NSE assuma um papel relevante nos debates sobre o espaço da economia na atualidade, parece necessário que ela avance além dos seus pressupostos básicos, buscando respostas às questões levantadas precedentemente. Dessa forma, o diálogo interdisciplinar com outras ciências sociais e, em particular, com a teoria das organizações, parece importante, visando recuperar a tradição nos estudos que tentam fazer uma ponte entre a economia e as relações sociais. A seguir destacamos algumas contribuições da teoria das organizações, reforçando o diálogo interdisciplinar e contribuindo para preencher algumas lacunas deixadas pelos estudos da NSE.

\section{CONTRIBUIÇÕES DA TEORIA DAS ORGANIZAÇÕES À NSE}

As contribuições da teoria das organizações que apontaremos aqui serão apresentadas pela abordagem dos seguintes temas: a organização como sistema social complexo e seu papel na composição dos mercados; a interação com o ambiente; a racionalidade dos atores econômicos; e a questão do poder nas organizações e na economia: aspectos micro e macro.

\section{Organização como sistema social complexo e seu papel na composição dos mercados}

Os estudos organizacionais têm avançado muito nos últimos anos na compreensão da complexidade das organizações e do seu papel na economia. Considerada nos primórdios da teoria das organizações como sistemas fechados, formados essencialmente por aspectos formais e tendo como objetivo o lucro, as organizações são encaradas na atualidade como sistemas complexos formados por múltiplas dimensões: econômica, técnica, humana, social, psíquica, cognitiva, política e cultural. Nesse processo, foi essencial a postura reflexiva de alguns autores da teoria das organizações sobre o seu próprio campo, buscando identificar os seus limites e superá-los. Conseqüentemente, as abordagens prescritivas e normativas têm sido confrontadas por análises empíricas, que partem do estudo de experiências vivenciadas no espaço organizacional.

É nesse contexto que ocorre o questionamento da visão funcionalista dominante em grande parte dos estudos organizacionais, caracterizada por uma visão sistêmica, sincrônica, teleológica, integradora e não conflituosa da organização (Chanlat e Séguin, 1992). No fim dos anos 1960, observa-se então um aumento do interesse pela análise crítica das organizações, movimento que se amplia nas décadas seguintes, inaugurando novas perspectivas para a análise organizacional. A partir de então, o debate com as ciências sociais se aprofunda, trazendo para o campo da teoria das organizações a discussão de temáticas não tratadas anteriormente, tais como as relações de poder dentro e fora das organizações, as questões ligadas à ideologia e a análise dos sistemas simbólicos. Vários autores passam a contestar a formação tecnicista dada aos administradores e a visão limitada do indivíduo e da própria organização que predominava nas teorias funcionalistas, propondo outras abordagens e lançando novas linhas de estudos no universo organizacional (Guerreiro Ramos, 1989; Chanlat, 1990; Acktouf, 1994). 
Acreditamos que tais estudos abrem um caminho para um entendimento das diferentes esferas da organização e de suas interações e, nesse sentido, podem permitir compreender melhor as "dimensões sociológicas" presentes no universo organizacional. Um maior diálogo da NSE com tais estudos representaria então novas possibilidades para entendimento desse "ator econômico", tão central na composição dos mercados, cuja lógica de funcionamento não é somente aquela definida por Weber quando estabeleceu o "tipo ideal" da burocracia.

\section{Interação com 0 ambiente}

A relação entre as organizações e o ambiente tem recebido uma atenção crescente dos autores da teoria das organizações nas últimas décadas. Uma das correntes tradicionais que dominou as análises nesse campo foi o chamado "modelo da seleção natural", baseado na biologia, segundo o qual os fatores ambientais selecionavam as organizações que melhor se adaptassem ao ambiente (Aldrich, 1971). Os princípios desse modelo tiveram uma grande aplicação nas primeiras fases dos estudos no campo da estratégia, onde se deu ênfase à questão do planejamento, sendo este concebido como uma reação das organizações às influências ambientais (Déry, 1995). Nessa concepção, o ambiente era então reduzido à sua dimensão econômica e formado pelos parceiros essenciais às empresas, no desempenho de seu negócio, quais sejam: fornecedores (de capital, de mão de obra e de insumos), concorrentes atuais e potenciais, e os clientes. As ações do Estado e dos demais agentes sociopolíticos seriam então mediadas por essas relações que a empresa teria com seus parceiros econômicos.

Com o avanço dos estudos no campo da estratégia e sua conseqüente institucionalização, pode-se perceber uma passagem da preocupação com o "planejamento" (dando ênfase à reação da empresa às pressões ambientais) para a preocupação com a "administração estratégica" (enfatizando a gestão das relações das empresas com seus diferentes stakeholders). Essa passagem coincide com uma mudança na própria concepção de ambiente. Um dos autores que define bem essa nova concepção é Pasquero (1989), o qual traz para o debate o conceito de ambiente sociopolítico que, por oposição, é definido não em relação a critérios econômicos, mas em termos de poder social. Segundo Pasquero, o ambiente sociopolítico compreende "os atores privados, públicos ou coletivos, que dispõem da capacidade de pesar sobre as decisões da empresa por outros meios que não aqueles colocados à disposição pelo mercado" (Pasquero, 1989, p. 117). Dessa forma, fazem parte do ambiente sociopolítico o Estado, os grupos de pressão (sindicatos, consumidores, ecologistas, movimentos sociais) e a comunidade.

Acreditamos que uma visão mais abrangente do ambiente sociopolítico-econômico deveria ser incorporada aos estudos realizados pela NSE, onde, pelos argumentos dos autores analisados, ainda prevalece uma visão "economicista" do ambiente. Assim, um diálogo maior com os autores no campo da teoria das organizações e, em particular, da estratégia na visão sociopolítica poderia ser enriquecedor, permitindo caracterizar de forma mais abrangente os atores do campo econômico e suas formas de influência.

\section{Racionalidade dos atores econômicos}

Os estudos sobre a racionalidade no âmbito das organizações ainda é um campo pouco explorado. Um dos autores que iniciou essa discussão, na década de 1960, e que ainda exerce influência nos estudos atuais foi Herbert Simon (1965). Analisando os processos de tomada de decisão nas organizações, Simon afirma que a racionalidade consiste no conhecimento absoluto das conseqüências das ações. Por conseguinte, é impossível que o comportamento de um único indivíduo seja considerado racional, daí o seu conceito de racionalidade limitada. Para o autor, somente os agentes corporativos e as organizações possuem a capacidade de agir racionalmente, pois "permitem uma abordagem razoavelmente próxima da racionalidade objetiva" (Simon, 1965, p. 80). Fica claro que a razão tratada por Simon é a razão instrumental, como descrita por Weber.

Na década de 1980, alguns trabalhos no âmbito da teoria das organizações vêm refutar os pressupostos de Simon (como Alvesson, 1985; Guerreiro Ramos, 1989; Serva, 1997a, 1997b). Inspirados na tradição da Escola de Frankfurt, em especial nos trabalhos de Habermas, esses autores salientam o papel de outras formas de racionalidade no âmbito organizacional. Alvesson (1985) afirma que nas organizações os grupos não desenvolvem apenas um, mas múltiplos padrões de racionalidade, apesar da racionalidade instrumental muitas vezes assumir um papel preponderante. Nesse sentido, ele defende a criação de espaços onde as outras formas de racionalidade possam ter expressão.

Guerreiro Ramos (1989) fundamentou seus estudos numa perspectiva mais ampla, denominada por ele "teoria substantiva da vida humana associada", inspirada na idéia de economia substantiva defendida por 
Karl Polanyi. Na elaboração dessa teoria, o autor analisa os trabalhos sobre racionalidade desenvolvidos por Thomas Hobbes, Max Weber, Karl Mannheim, Eric Voegelin e pelos autores da Escola de Frankfurt, chegando ao conceito de "racionalidade substantiva", o qual se fundamenta no sentido aristotélico de ética e constitui uma categoria-chave para compreender a ação dos indivíduos nas organizações. A racionalidade substantiva para Guerreiro Ramos seria um atributo natural do ser humano que permitiria contrabalançar a busca de emancipação e auto-realização, com alcance de satisfação social, ou seja, considerando também o direito dos outros indivíduos de fazê-lo. A razão substantiva apresentada pelo autor se contrapõe então à razão instrumental e tem sua base no julgamento ético-racional.

Fazendo uma ponte entre o trabalho de Guerreiro Ramos e a teoria da ação comunicativa elaborada por Habermas, Serva (1997a, 1997b) buscou analisar a presença da racionalidade substantiva na prática administrativa. A racionalidade substantiva é definida por Serva como ação orientada para duas dimensões: a da auto-realização (compreendida como concretização de potencialidades e satisfação) e a social (que se refere ao entendimento nas direções da responsabilidade e satisfação sociais). O autor realizou estudos empíricos em três empresas de serviços, buscando identificar em que medida essa racionalidade se apresentava em seus processos administrativos. Os resultados das pesquisas demonstraram que nas três organizações, em um grau maior ou menor, os dois tipos de racionalidades estavam presentes, sendo então crucial a questão da predominância.

Sem exaurir o debate, percebe-se que as pesquisas sobre a racionalidade no campo das organizações indicam algumas pistas e caminhos que podem ser aproveitados pelos pesquisadores da NSE, especialmente no que se refere à abordagem de outras formas de racionalidade que influenciam a ação dos agentes econômicos. Conseqüentemente, poder-se-ia ter uma visão mais clara da influência dessas outras modalidades de racionalidade nos espaços do mercado formal e fora dele.

\section{A questão do poder nas organizações e na economia: aspectos micro e macro}

A busca da compreensão da influência das relações de poder dentro e fora do universo organizacional tem guiado o interesse de diversos pesquisadores no campo da teoria das organizações, especialmente após a década de 1960, a partir da ampliação da influência das abordagens críticas. Inicialmente interessados em analisar o poder no interior das organizações, esses pesquisadores se concentraram em identificar as fontes, os métodos e as implicações do poder nas organizações (Handy, 1978). Num segundo momento, as pesquisas se voltaram também para a compreensão do ambiente externo, buscando ir além das fronteiras da organização.

Benson (1977) é um dos autores que avançam nessa direção. Tendo por base a concepção dialética, o autor defende a noção de organização como uma totalidade, remetendo aos elos entre as organizações e a sociedade. Além disso, estabelece dois âmbitos de análise das organizações: os aspectos morfológicos, referente aos objetivos, arranjos estruturais e relações formais com o ambiente; e a "infraestrutura" organizacional (composta pelos aspectos não racionalizados da ação, as ideologias e as relações de poder, que permeiam a realidade interna e externa da organização).

Mintzberg (1995) complementa o trabalho de Benson e de outros autores, buscando construir uma teoria do poder que leva em conta a realidade organizacional contemporânea. A partir de estudos empíricos, esse autor propõe um modelo de análise do poder nas organizações no nível micro (interno) e no nível macro (externo). Nesse modelo, Mintzberg define o intricado campo de influência e os grupos de interesse, assim como as coalizões que se formam entre eles, dentro e fora das organizações.

Considerando os aprendizados obtidos nesse campo, sugere-se que um diálogo da NSE com as teorias que tratam a questão do poder nas organizações poderia conduzir a uma clareza maior sobre os atores, as fontes e as configurações de poder que compõem as organizações e o mercado, fornecendo pistas para novos estudos sobre o tema.

\section{CONTRIBUIC̄̃̃ES DA NSE À TEORIA DAS ORGANIZAÇÕES}

Dando continuidade ao esforço de auxílio à construção de saberes interdisciplinares, apresentamos algumas contribuições que a NSE poderia fornecer para o enriquecimento da teoria das organizações. Os temas sugeridos são: competição empresarial, grupos empresariais e empreendedorismo.

\section{Competição empresarial}

A "dimensão social do mercado", uma das temáticas mais trabalhadas pela sociologia econômica, abre no- 
vos e amplos horizontes para várias correntes da teoria das organizações, como também para algumas áreas aplicadas da Administração. A consideração do mercado como instituição conduz a sociologia econômica ao estudo da competição entre empresas. Tal tema de estudo ganha uma importância crescente no quadro atual da intensificação da internacionalização dos mercados, ou ainda, da globalização, como preferem denominá-la alguns autores. Fala-se muito atualmente em "competição global", "competição acirrada", "competitividade", dentre outras expressões para representar seja a situação de concorrência que caracteriza o ambiente das empresas contemporâneas, seja a condição que estas últimas necessitam atingir para continuar existindo nesse ambiente.

Os instrumentos teóricos disponíveis na teoria administrativa não dão conta da influência das variáveis de natureza social na competição empresarial. Na grande maioria dos estudos que abordam esse tema na Administração, a competição é uma realidade a enfrentar e a superar por meio da sagacidade dos administradores, expressada pela sua capacidade de perceber as mudanças ambientais e de agir rápida e estrategicamente. O problema é que os instrumentos utilizados para a percepção dessas mudanças têm como pressupostos fundamentais os aspectos técnicos e econômicos concernentes à competição, tais como dimensão tecnológica, soluções de logística, índices econômicos, disponibilidade de capital, economias de escala, sistema de preços, quantidade de competidores, dentre outros, com exceção feita a poucos aspectos de natureza subjetiva, como, por exemplo, a preferência dos consumidores. Entretanto, a flutuação da preferência dos consumidores e suas variáveis simbólicas correlatas representam apenas uma espécie de ponta do iceberg em face dos demais fatores sociais envolvendo a competição.

Nesse sentido, Etzioni (1988) chega a afirmar que a competição empresarial é um processo "socialmente encapsulado". Para o autor, a competição é uma forma de conflito organizado e enquadrado socialmente, o que permite a sua limitação e também a sua sustentação. Ele aponta três mecanismos de sustentação da competição: fatores normativos (confiança, custos de transação), limites sociais estabelecendo um meio-termo entre os sistemas impessoais/calculistas e a densidade comunal, e por último a regulação exercida pelo Estado. Nessa interpretação, o Estado é necessário para a manutenção da "cápsula", sendo em última instância o árbitro dos conflitos. Etzioni acredita que quanto mais fortes forem os fatores normativos e os limites sociais, menor será a necessidade de regulação exercida pelo Estado, devido à dinâmica de interação entre os três mecanismos.

Semelhante posição é adotada por Abofalia e Biggart (1991). Esses autores propõem uma concepção da competição, sobretudo como uma forma de espaço coletivo institucionalmente encastoado e socialmente mantido. Três aspectos constituem sua perspectiva analítica: a competição como uma forma de ação social orientada pela interação com os outros atores, o surgimento de padrões e normas decorrentes da ação competitiva em mercados relativamente estáveis, e o estabelecimento de suportes para regulação e sustentação da competição.

Ao delinear outras dimensões da competição empresarial que não somente a tecnológica e a econômica, a sociologia econômica acrescenta um importante elemento para a percepção mais acurada do funcionamento do mercado, fornecendo uma contribuição indispensável à teoria das organizações.

\section{Grupos empresariais}

Ainda na esfera empresarial, chamamos a atenção para uma outra contribuição da sociologia econômica: o estudo dos grupos empresariais. Hoje vivemos num período histórico em que determinados grupos empresariais aumentaram consideravelmente o seu poder, provocando inclusive o enfraquecimento do Estado frente às questões econômicas. Uma boa parte dos produtos e serviços dos quais necessitamos na vida urbana cotidiana provêm dos grandes grupos empresariais, principalmente dos multinacionais. Apesar de eles se constituírem num dos aspectos de grande interesse nas escolas de Administração, a teoria das organizações conta com parcos estudos enfocando os grupos empresariais como objeto central. Em geral, os trabalhos realizados sobre os grandes grupos empresariais abordam aspectos específicos da sua gestão, como a ação estratégica adotada e seus resultados num determinado período, as relações de trabalho em algumas unidades do grupo, a entrada em um novo mercado, a governança corporativa, mas dificilmente buscam esclarecer a origem e as formas de manutenção do grupo em si.

Granovetter (1994) dá um passo decisivo para a consideração dos grupos empresariais como objeto de estudo numa perspectiva de análise comparativa. Para tanto, o autor estabelece seis dimensões de variação desses grupos: as relações de propriedade, os princípios de solidariedade, a estrutura de autoridade, a dimensão moral, as finanças e as relações com o Estado. 
As relações de propriedade provocam variações essenciais de um grupo a outro conforme sejam eles controlados direta ou indiretamente por uma pessoa, uma família ou um conjunto de famílias correlacionadas. Há também que considerar as formas específicas de estrutura societária que se configuram às vezes por meio de uma holding company, ou ainda de um tipo de federação entre empresas. Dentre os princípios de solidariedade se encontram a região, o partido político, a etnia, o parentesco e a religião. Para Granovetter (1994), em países como o Brasil, a mistura de princípios das relações com grupos estrangeiros, relações especiais com o Estado e com as elites financeiras locais são determinantes para o crescimento e a manutenção dos grupos empresariais de grande porte. De forma geral, a multiplicidade de bases de solidariedade deve ser identificada para alcançar uma compreensão melhor do fenômeno. A estrutura de autoridade pode ter uma direção dominantemente vertical ou horizontal, dando os contornos da concentração ou da distribuição do poder no seio do grupo. A configuração dessa estrutura guarda uma relação estreita com a origem e a história do grupo: por exemplo, ela tende a ser muito diferente no caso da sua origem ter sido uma empresa apenas ou uma coalizão de empresas. O exame da existência e força dos valores morais e sua compatibilidade ou não com os principais valores presentes na cultura da região de origem do grupo pode ajudar a explicar muitas vezes o crescimento, o desaparecimento ou simplesmente o modo de funcionamento de alguns grupos empresariais. As formas de mobilização de capital e as relações com o Estado correspondem mais proximamente à ação ambiental dos grupos empresariais. Em particular, a dinâmica das interações dos grupos com os bancos é um dos aspectos cruciais para a sua manutenção, representando também um fator de variabilidade intergrupos digno de destaque. As relações com o Estado, por sua vez, são tão complexas e diferenciadas que merecem uma abordagem especial para a sua apreensão. A aproximação entre os grupos empresariais e o Estado pode assumir várias formas. O conteúdo das políticas públicas de desenvolvimento pode ser essencial para a estrutura organizacional e as ações de determinados grupos num período de tempo. Atores que partem de instâncias do Estado acabam por ocupar postos de comando em grupos empresariais e vice-versa, caracterizando o fenômeno da tecnoburocracia. Não é novo lembrar que diversos grupos empresariais estiveram na base de golpes de Estado em várias partes do mundo durante o século passado. É sempre necessário estudar o fenômeno da transposição do poder econômico em poder político, tendo em vista a interferência de alguns grupos empresariais no destino de uma comunidade. Granovetter ressalta que as seis dimensões de variação acima listadas devem ser alvo de uma elaboração teórica considerando-se o contexto histórico institucional e desprezando-se correlações empíricas fixas entre elas.

$\mathrm{O}$ foco centrado nos grupos empresariais como objeto de análise é uma contribuição de peso da sociologia econômica para a teoria das organizações. Enquanto a teoria administrativa tem abordado aspectos específicos, ensejando uma frágil e esparsa compreensão do funcionamento desses grupos, a análise global deles evidentemente promoveria uma visão não fragmentada da realidade organizacional. Adotando essa opção, a teoria das organizações se concentraria prioritariamente no exame do grupo empresarial em si como um ator coletivo, buscando identificar as diversas variáveis - e suas relações que caracterizam suas dimensões socioeconômicas. Após ter investido no delineamento do objeto, o passo seguinte seria o exame de aspectos específicos, inclusive daqueles de cunho mais técnico, pois ligados à gestão. Operando dessa forma, a teoria das organizações poderia consolidar programas de pesquisa numa base mais substantiva, uma vez que tais programas estariam relacionados às condições reais de ação dos grupos empresariais, isto é, ancorados na análise dos processos sociais e políticos que permeiam suas atividades econômicas e administrativas.

\section{Empreendedorismo}

Nos últimos anos, o tema do empreendedorismo vem ganhando espaço crescente nas escolas de Administração e na mídia em geral. O agravamento da crise econômica iniciada desde os anos 1970 teve como uma de suas conseqüências principais o desemprego, que, por sua vez, aprofunda a crise social em todos os países. A forte diminuição do ritmo de crescimento econômico muda radicalmente o regime dominante de acumulação do capital, desprezando durante quase 30 anos consecutivos o ideal do pleno emprego outrora considerado como um dos pilares do desenvolvimento do sistema e do equilíbrio social. Nesse contexto, observa-se a proliferação de incentivos a uma certa "capacidade de iniciativa" dos indivíduos, no sentido de eles se lançarem como empresários, criando negócios e deixando de lado a busca do emprego com as sonhadas boa remuneração e estabilidade. O impacto desses movimentos no ambiente acadêmico tem sido 
significativo. Na Administração, o empreendedorismo passou a ser tema central de vários cursos de extensão, como também disciplina obrigatória em cursos de graduação, enquanto que na Economia ganham novo interesse determinados estudos, como o de Schumpeter, que apontam as características do empreendedor como um ator social.

Os estudos realizados por autores ligados à sociologia econômica têm revelado dimensões do empreendedorismo que contribuem não somente para delinear o ambiente institucional onde o empreendedor age, como também para deslindar aspectos constitutivos das relações sociais no seio das quais a ação empreendedora é possível. Stevenson e Jarillo (1991) revisam grande parte dos estudos realizados sobre empreendedorismo e constatam que estes falham em geral por confundir inteiramente o campo do empreendedorismo com o de pequenos negócios, ou ainda por não examinar os complexos dilemas que o empreendedor regularmente enfrenta. Os autores adotam como ponto de partida a visão do empreendedorismo como um processo e propõem um quadro de análise com o objetivo de auxiliar o aperfeiçoamento das práticas de gestão no âmbito do empreendedorismo. As variáveis principais desse quadro de análise são a orientação estratégica, o comprometimento com a oportunidade, o controle de recursos, a estrutura de gestão e as políticas de recompensa. Nesta última variável, ressaltamos a inclusão de indicadores como normas sociais, demandas de públicos externos à organização e soluções para questões relativas à equidade na distribuição das recompensas.

Para Martinelli (1994), o empreendedor é um ator social que exerce papéis fundamentais em instituiçõeschave da economia de mercado e que por isso acaba por ocupar posições importantes na sociedade capitalista. O autor desenvolve um estudo sobre empreendedorismo discutindo criticamente as abordagens contemporâneas do fenômeno: origens sociais e traços psicológicos do empreendedor, contexto de surgimento do empreendedorismo, relações entre empreendedorismo e cultura, abordagem situacional (como agem os empreendedores). Martinelli conclui que essas abordagens concentram seus esforços na formação do empreendedor, deixando de lado alguns temas importantes, os quais devem guiar a pesquisa futura, quais sejam: a sucessão em empresas familiares, o papel do empreendedor em organizações sem fins lucrativos e a análise de insucessos na atividade empreendedora.

Starr e MacMillan (1991) analisam as ações do em- preendedor no meio institucional para a mobilização de recursos geralmente escassos. Os autores empreendem um estudo empírico com diversos casos que ilustram como "os empreendedores adquirem recursos para seus negócios utilizando estratégias socioeconômicas" (Starr e MacMillan, 1991, p. 169). As estratégias são divididas em quatro conjuntos: cooptação de recursos estratégicos (influência, amizade, favores), cooptação de "bens públicos" (legitimidade, acesso à mídia, endossos, informação, confiança), cooptação de bens subutilizados (empréstimos e obtenção definitiva de materiais, equipamentos, instalações). A esse processo como um todo os autores denominam "construção de ativos sociais", demonstrando a dimensão social da ação econômica do empreendedor na busca dos recursos necessários ao seu negócio.

Mesmo pelo breve inventário acima, é possível perceber a contribuição que a sociologia econômica pode dar à teoria das organizações no tratamento do tema do empreendedorismo. Mais importante, cremos, é a constatação do potencial dos estudos baseados na orientação da sociologia econômica para o enriquecimento da interpretação de quem é o empreendedor e de como ele atua, em face das condições sociais e econômicas que caracterizam seu contexto. A partir dessas contribuições, a teoria administrativa poderá melhor delinear as formas de gestão adequadas para a atividade empreendedora.

\section{CONSIDERAÇÕES FINAIS}

Pretendemos com este trabalho levantar alguns temas que poderiam ser enriquecidos no âmbito da sociologia econômica, a partir de um maior diálogo com a teoria das organizações. Para tanto, no âmbito da sociologia econômica buscamos situar uma de suas correntes mais importantes: a NSE, destacando os seus pressupostos. A partir do levantamento de algumas lacunas deixadas no debate atual da NSE, buscamos identificar temáticas que poderiam ser aprofundadas, na perspectiva de uma construção interdisciplinar oriunda de uma maior aproximação com os estudos organizacionais. Ressaltamos especialmente a organização como sistema social complexo e seu papel na composição dos mercados, a interação com o ambiente, a racionalidade dos atores econômicos, a questão do poder nas organizações e na economia em seus aspectos micro e macro. Cremos que um dos caminhos mais promissores para o preenchimento dessas lacu- 
nas é a abertura efetiva dos autores da NSE para determinados estudos organizacionais elaborados desde os anos 1970 e que não estão inseridos no paradigma funcionalista. Arriscamos a afirmar que quanto mais distantes os autores da NSE se posicionarem dessa abertura, ignorando essa importante produção do campo da teoria das organizações, maior será a probabilidade de ampliação das referidas lacunas no seu próprio campo.

Mas se o esforço for abrir avenidas para a interdisciplinaridade, o diálogo deverá ser de mão dupla. Dessa forma, não contribuirá somente para o avanço da NSE, mas também poderá enriquecer a teoria das organizações, que em grande medida poderá se beneficiar dos estudos empreendidos por pesquisadores da NSE sobre os temas da competição empresarial, dos grupos empresariais e do empreendedorismo, dentre outros.

O levantamento temático aqui realizado está muito longe de esgotar o inventário das contribuições da teoria das organizações à sociologia econômica e vice-versa. Nossa intenção foi apenas ilustrar a natureza dessas contribuições e assinalar a sua importância para o desenvolvimento de ambas as disciplinas. Menos do que registrar as contribuições em questão, tentamos proporcionar a percepção do potencial da colaboração interdisciplinar para o enriquecimento desses dois campos de estudo.

$\mathrm{Na}$ medida em que se reforçam os diálogos interdisciplinares, a análise da intersecção entre economia e sociologia deixa de ser o objeto de pesquisa da sociologia econômica e passa a ser incorporada pelo conjunto das ciências sociais. Dessa forma, se poderá dar mais consistência ao debate e construir um "olhar" para além dos muros disciplinares, que permita enxergar com mais clareza a influência recíproca dos fenômenos econômicos, políticos, sociais e organizacionais na modernidade.

Sob outro prisma, fazer avançar a compreensão da realidade organizacional parece ser uma das vias para tornar as organizações produtivas espaços onde a democracia, os direitos humanos e os ideais ligados à emancipação humana tenham lugar. Hoje vivemos num tipo genérico de sociedade em que a densidade organizacional é a mais elevada da história. Dependemos como nunca das organizações para satisfazer a maior parte de nossas necessidades; dessa forma, elas se tornaram o palco privilegiado da cena social, onde nós, atores em busca da auto-realização, interagimos sem cessar, encenando peças das mais importantes de nossas vidas. A sociologia econômica vem aperfeiçoando suas possibilidades de levantar questões e propor vias de diálogo para a compreensão mais ampla das questões que afetam a vida social. A prática da interdisciplinaridade é um recurso essencial para que essas possibilidades se concretizem cada vez mais. Compreender é fundamental para agir com consciência. Na sociedade organizacional atual, muito há que ser feito para torná-la mais justa e apropriada à auto-realização dos seus membros. A contribuição dada ao conhecimento sobre a ação coletiva nas organizações produtivas adquire uma importância capital para que essa ação seja empreendida a favor do ser humano.

\section{NOTA}

${ }^{1}$ Em particular, destaca-se o diálogo com os autores no âmbito da teoria das organizações que se inserem no campo da economia neoclássica, tais como Williamson, ou ainda sociólogos que atuam no campo das organizações, como Chandler, Etzioni e Sansaulieu. Acreditamos que essa aproximação ainda é insuficiente para explorar as possibilidades de intercâmbio de aprendizados entre os campos disciplinares aqui tratados.

\section{REFERÊNCIAS BIBLIOGRÁFICAS}

ABOFALIA, M.; BIGGART, N. Competition and markets: an institutional perspective. In: ETZIONI, A.; LAWRENCE, P. (Eds.) Socio-Economics Toward a New Synthesis. New York: M. E. Sharp, 1991.

ACKTOUF, O. Le management entre tradition et renouvellement. Montréal: Gaetan Morin, 1994

ALDRICH, H. E. Organizational boundaries and interorganizational conflict. Human Relations, v. 24, p. 279-87, 1971.

ALVESSON, M. A critical framework for organizational analysis. Organization Studies, v. 6, n. 2, p. 117-139, 1985.

BENSON, J. K. Organizations: a dialectical view. Administrative Science Quarterly, v. 22, n. 1, p. 1-21, 1977.

BOURDIEU, P. Le champs économique. Actes de la Recherche en Sciences Sociales, v. 119, p. 46-66, 1997.

CAILLÉ, A. Préface. In: SWEDBERG, R. Une histoire de la sociologie économique. Paris: Desclée de Brouwer, 1994.

CHANLAT A.; DUFOUR M. (Eds.) La rupture entre les enterprises et les hommes. Québec: Québec/Amérique, 1985.

CHANLAT, J.-F. (Ed.). Lindividu dans l'organisation - les dimensions oubliées. Québec: Les Presses de l'Université Laval, 1990.

CHANLAT, A.; SÉGUIN F. (Eds.). L'analyse des organisations. Montréal: Gaetan Morin, 1992. 
DÉRY, R. La structuration socio-historique du champ de la stratégie. In: QUATRIÈME CONFERENCE DE LASSOCIATION INTERNATIONALE DE MANAGEMENT STRATÉGIQUE. Anais. Paris: AIMS, 1995.

ETZIONI, A. Organizações modernas. São Paulo: Pioneira, 1976.

ETZIONI, A. The Moral Dimension: Toward a New Economics. New York: The Free Press, 1988.

FLIGSTEIN, N. Market as politics: a political-cultural approach to market institutions. American Sociological Review, v. 61, p. 656-673, 1996.

GRANOVETTER, M. Le marché autrement: essais. Paris: Desclée de Brouwer, 2001.

GRANOVETTER, M. Business groups. In: SMELSER, N.; SWEDBERG, R. (Eds.). The Handbook of Economic Sociology. Princeton: Princeton University Press, 1994.

HANDY, C. Como compreender as organizações. Rio de Janeiro: Zahar, 1978.

LÉVESQUE, B.; BOURQUE, G.; FORGUES, É. La nouvelle sociologie économique. Paris: Desclée de Brouwer, 2001.

MARTINELLI, A. Entrepreneurship and management. In: SMELSER, N.; SWEDBERG, R. (Eds.). The Handbook of Economic Sociology. Princeton: Princeton University Press, 1994.

MINTZBERG, H. Power in and around Organizations. Englewood Cliffs, NJ: Prentice Hall, 1995.
PASQUERO, J. Gérer stratégiquement dans une économie politisée. Gestion, v. 14, n. 3, 1989.

PERRET, B. Préface. In: LEVESQUE, B.; BOURQUE, G.; Forgues, É. La nouvelle sociologie économique. Paris: Desclée de Brouwer, 2001.

GUERREIRO RAMOS, A. A nova ciência das organizações. Rio de Janeiro: Editora da Fundação Getúlio Vargas, 1989.

SERVA, M. A racionalidade substantiva demonstrada na prática administrativa. Revista de Administração de Empresas, v. 37, n. 2, p. 18-30, 1997.

SERVA, M. Abordagem substantiva e ação comunicativa: uma complementaridade frutuosa para a teoria das organizações. Revista de Administração Pública, v. 31, n. 2, p. 108-34, 1997.

SIMON, H. Administrative Behavior. New York: The Free Press, 1965.

STARR, J.; MACMILLAN, I. Entrepreneurship, resource cooptation, and social contracting. In: ETZIONI, A.; LAWRENCE, P. (Eds.). Socio-Economics: Toward a New Synthesis. New York: M. E. Sharp, 1991.

STEVENSON, H.; JARILLO, J. A new entrepeneurial paradigm. In ETZIONI, A.; LAWRENCE, P. (Eds.) Socio-Economics: Toward a New Synthesis. New York: M. E. Sharp, 1991.

SWEDBERG, R. Une histoire de la sociologie économique. Paris: Desclée de Brouwer, 1994

\section{Artigo recebido em 08.12.2004. Aprovado em 13.01.2006.}

\section{Maurício Serva}

Professor da PUC-PR. Presidente, no Brasil, do CIRIEC - Centro Internacional de Pesquisa e Informação sobre a Economia Pública, Social e Cooperativa. Doutor em Administração pela FGV-EAESP, com pós-doutorado em Autonomia e Gestão Social na HEC Montréal.

Interesses de pesquisa nas áreas de epistemologia da Administração, teoria das organizações, ação coletiva, organizações da sociedade civil, desenvolvimento territorial sustentável.

E-mail: mserva@terra.com.br

Endereço: PUC-PR - PPAD, Rua Imaculada Conceição, 1155, Bloco Acadêmico, Curitiba - PR, 80215-901.

\section{Carolina Andion}

Professora da UNIFAE. Doutoranda em Ciências Humanas na UFSC e pesquisadora do CIRIEC. Interesses de pesquisa em organizações da sociedade civil, economia social e solidária, ação coletiva, desenvolvimento territorial sustentável, responsabilidade social, teoria e estudos organizacionais.

E-mail: carol.andion@terra.com.br

Endereço: Rua República Islâmica do Irã, 316/2, Jardim das Américas, Curitiba - PR, 81540-600. 